\title{
Examining Implementation of Policy Effects on Coronavirus (Covid-19) in United State of America
}

\author{
Alexandra Adetutu Oseni \\ Southern University and A \& M College, Department of Public Administration/Policy, Baton Rouge, Louisiana, \\ USA
}

\begin{abstract}
This particular study examines public policy implementation theories on the various interventions to combat the Coronavirus (COVID-19) pandemic. As underscored in the literature COVID-19 is perceived to be a respiratory disease caused by a novel Coronavirus. The virus was first noticed in Wuhan in China. This global killer-COVID19 has caused many countries, including the United States of America, to get on rigorous policies measures to help contain the spread. Some of the perceived preventive measures taken by the United States of America include travel restrictions, official and self quarantines, postponements of events facility closures and curfews. All these are possible immediate solution proposed by healthcare experts and professionals to flatten the COVID-19 curve. As a result of adding to public policy literature and to also assist policymaker to understand the implication of their choice of intervention procedures, the study uses the two main approaches of policy or program implementationtop-down and bottom-up to all governors, decision makers on possible ways to approach pandemic issues. In the face of this COVID-19 pandemic, the study recommended that all preventive care, possible treatment tools (or medication), screening and if possible vaccination must be either free or demanded at a subsidized rate in order make eradication possible (see Table 1 for more details).

Keywords: Theory, Implementation, Policies, Coronavirus, Eradication, Preventive, Interventions, Subsidy, Health, Healthcare, Practitioners, Respiratory.
\end{abstract}

DOI: $10.7176 / \mathrm{JLPG} / 96-14$

Publication date: April $30^{\text {th }} 2020$

\section{INTRODUCTION}

It is an undeniable fact that policy implementation is paramount to policy outcomes. As a result, many organizations, businesses, governments, schools, hospitals, and other human institutions rely heavily on the execution process and method of required mandates or task to achieve its expected outcomes. In fact, program implementation is about making a program work. It includes who, what, where, and how a program is set up and run. The COVID-19 Emergency Team for the nation initiatives work within contexts that are complex, fragmented, and often vulnerable to changes in political and economic climates for all states in the United States of Americafor all things that can work with or against a program's or policy's ability to achieve results. Meanwhile, it has been underscored in the policy/program evaluation literature that an effective implementation is more than a contributing factor in setting initiatives up for success. According to Durlak (2011), the quality of implementation plays a significant part in bringing about outcomes. Therefore, if COVID-19 combat program initiatives in United States of America are implemented poorly or even moderately well, its goals are unlikely to be achieved, or the results will be less significant to the performance standard (or target). This implies that with high quality implementation for COVID-19 eradication programs, success is more likely to be achieved, thereby flattening the curve. Based on literature, I can underscore emphatically that effectively implemented programs or policies stand a better chance of achieving intended outcomes and producing positive results for all Americans. This is why all programs and policies geared towards the eradication of COVID-19, their respective implementation procedures and methods/theories are of major concerns to academia, scholars and policymakers. The two major policy implementation theories include top-down and bottom-up. The validity of these two options in program/policy implementation and whether there are one-fits-all arguments for these theories is also a matter of concern in contemporary policy research. In pandemic situations such as the COVID-19 outbreak caused by the Coronavirus, either a top-down approach or bottom-up approach or mixed approaches are/is expected to be utilized to ensure a successful program/policy implementation in the form of effective interventions. 


\section{HISTORICAL INFORMATION ABOUT THE CONFIRMED CASES OF COVID-19}

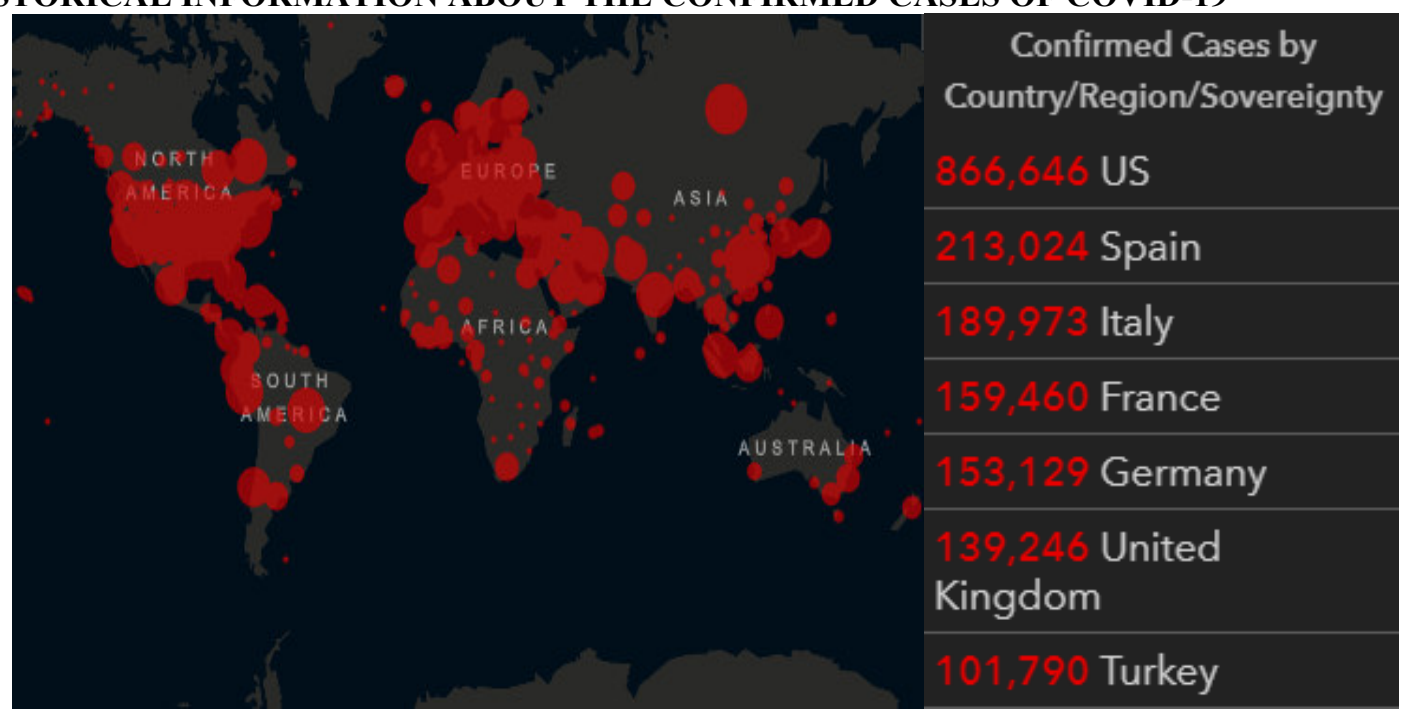

Figure 1: A Map Showing Leading Countries in COVID-19 Confirmed Cases

Source: Author's Modification of John Hopkins University and Medicine Cumulative Confirmed Cases of COVID 19.

The novel coronavirus, commonly referred to as the global pandemic COVID-19 has without warning disrupted democracies, shocked economies and forever changed life as many humans globally know it (see Figure 1 for more details). According to the United States Center for Disease Control (2020), the Coronavirus disease 2019 (COVID-19) is a respiratory illness that can spread from person to person. The virus that causes COVID-19 is a novel coronavirus that was first identified during an investigation into an outbreak in Wuhan, China. This COVID-19 respiratory disease caused by a novel coronavirus that was first detected in Wuhan in China but has currently been detected in over 70 geographic locations worldwide, including the United States of America (Centers for Disease Control and Prevention, 2020).

Historically, coronavirus is observed in the literature to be part of a large family of viruses, which are common in humans and many different species of animals and other non-humans, including camels, cattle, cats, bats and many others (Centers for Disease Control and Prevention, 2020). According to Centers for Disease Control and Prevention (2020), non-human coronaviruses can infect humans and subsequently spread among people such as with the conventional viruses with MERS-CoV, SARS-CoV, and, now, with this new virus (named as SARS-CoV2 or COVID-19) (Centers for Disease Control and Prevention, 2020).

According to CDC (2020), the SARS-CoV-2 virus is a betacoronavirus, which can spread and infect people like MERS-CoV and SARS-CoV. Surprisingly, all such types of viruses as SARS-CoV-2 or COVID-19, MERS-CoV and SARS-CoV have their origins in bats (CDC, 2020). Therefore, it has been alleged in numerous reports that many of the patients at the epicenter of the outbreak in Wuhan, Hubei Province, China had some link to large seafood and live animal markets, thereby suggesting that animal-to-person spreading of the virus is possible (Centers for Disease Control and Prevention, 2020). It has also been observed by several citizens and physicians that a growing number of patients also did not have exposure to animal markets, indicating person-toperson spread of the virus (CDC, 2020).

It was also reported that person-to-person spread of the virus was subsequently found outside Hubei and in countries outside China, including in the United States of America, Italy, and many other countries. It has been further noticed in the literature that some international destinations now have apparent community spreading of the virus that causes COVID-19 (Centers for Disease Control and Prevention, 2020). A columnist in The Washington Post stated, the prime suspect is "natural" transmission from bats to humans, perhaps through unsanitary markets (Ignatius, April 2, 2020). Another possibility from the same source claims scientists suggest a Wuhan research laboratory accident where a sample of the deadly virus had been collected might have been the genesis (Ignatius, April 2, 2020).

While research and genetic sequencing has proven that the first COVID-19 case in Wuhan was from a bat it is not clear how the virus was shared with a human. Did the human eat the bat? Did the human eat another animal that had contact with bats? Did an animal that had contact with a bat also have contact with a human? Ignatius also reported in The Washington Post, a competing theory - of an accidental lab release of bat coronavirus spread (Ignatius, 2 April 2020). Less than 300 yards from the seafood market is the Wuhan branch of the Chinese Center for Disease Control and Prevention spread (Ignatius, 2 April 2020). Researchers from that facility and the nearby Wuhan Institute of Virology have posted articles about collecting bat coronaviruses from around China, for study to prevent future illness. Did one of those samples leak, or was hazardous waste deposited in a place where it could 
spread (Ignatius, 2 April 2020). There are many questions that loom that one must consider when investigating from a public policy perspective. For example, is there a definitive determination on how the outbreak occurred and the spread began? Policymakers must without bias analyze all possibilities to ensure the programs or policies recommended for COVID-19 eradication are best implement given the agreed state of affairs.

According to Huang et al.(2020), the 2019-20 coronavirus pandemic is an ongoing situation of coronavirus disease of 2019 (COVID-19), which is caused by severe acute respiratory syndrome, thus coronavirus 2 (SARSCoV-2). The outbreak was first identified in Wuhan and Hubei in China in December of 2019, and it was recognized as a pandemic by the World Health Organization (WHO) on 11th March 2020 (Huang et al., 2020; Worldometer, 2020; World Health Organization, 2020). As of 25th March 2019 it was reported that more than 422,000 cases of COVID-19 had have been reported in more than 190 countries and territories, resulting in more than 18,900 deaths and more than 109,000 recovered patients (Huang et al., 2020; Worldometer, 2020; World Health Organization, 2020). In the literature, the World Health Organization (2020) and Centers for Disease Control and Prevention (2020) concurrently have the argument that the virus is typically spreading during close contact and through respiratory droplets produced when people cough or sneeze. Whenever an infected person coughs or sneezes, it increases the prevalence and hazardous rate. Therefore, the respiratory droplets may be produced during breathing but it is not considered airborne (World Health Organization, 2020). Meanwhile, theses two agencies further argued that the COVID-19 may also spread when one touches a contaminated surface and then touches their face (World Health Organization, 2020; Centers for Disease Control and Prevention, 2020). It is most contagious when people are symptomatic, although spread may be possible before symptoms appear (Centers for Disease Control and Prevention, 2020). It has also been observed in the literature that the time between exposure and symptom onset is typically around five days, but may range from two to fourteen days (Centers for Disease Control and Prevention, 2020; Rothan and Byrareddy, 2020).

The fourteen- day period is also known as the incubation period for COVID-19. The Centers for Disease Control and Prevention (2020) further argued that the obvious or most common symptoms for identifying a COVID-19 patient or infection include fever, dry cough, and shortness of breath. They have further indicated that the complications may include pneumonia and acute respiratory distress syndrome (Centers for Disease Control and Prevention, 2020). Currently, it is obvious that there is no known vaccine or specific antiviral treatment. As a result, it has been proposed by the numerous healthcare providers that the primary treatment is symptomatic and supportive therapy (Centers for Disease Control and Prevention, 2020). Also, recommended preventive measures include hand washing, covering the mouth when coughing, maintaining distance from other people, and monitoring and self-isolation for people, who suspect that they are infected or has been exposed to an infected person (World Health Organization, 2020; Centers for Disease Control and Prevention, 2020).

The pandemic nature of COVID-19 has caused many countries to get on severe measures. In fact, many of the affected countries have used the following efforts to prevent the spreading of the COVID-19-travel restrictions, quarantines, event postponements and facility closures, curfews and self-isolation. These have included the quarantine of Hubei, nationwide quarantines in Italy, quarantine in USA, quarantine in Ghana, elsewhere in Europe, Africa and in India, curfew measures elsewhere in China, Ghana and South Korea (Marsh, 2020; Nikel, 2020); various border closures or incoming passenger restrictions (The Straits Times, 2020; Nevada Public Radio, 2020); screening at airports and train stations (South China Morning Post, 2020; Marsh, 2020; Nikel, 2020; The Straits Times, 2020; Nevada Public Radio, 2020; Deerwester and Gilbertson,2020; The New York Times, 2020); and travel advisories regarding regions with community transmission (Deerwester and Gilbertson, 2020; The NewYork Times, 2020; The Government of the United Kingdom, 2020; UNESCO, 2020); Schools and universities have closed either on a nationwide or local basis in more than 124 countries, affecting more than 1.2 billion students across the globe (The New York Times, 2020). All these are possible immediate solution proposed by healthcare experts and professionals to flatten the COVID-19 curve to minimize the spreading of the virus.

The pandemic has led to global socio-economic disruption (The NewYork Times, 2020), the postponement or cancellation of sporting, religious, and cultural events (The NewYork Times, 2020; Scipioni, 2020), and widespread fears of supply shortages which have spurred panic buying (Scipioni, 2020;Council on Foreign Relations, 2020; Misinformation and conspiracy theories about the virus have spread online (Perper, 2020; Clamp, 2020), and there have been incidents of xenophobia and racism against Chinese and other East or Southeast Asian people (Tavernise, Oppel, and Richard, 2020). As a result of adding to public policy literature and to also assist policymaker to understand the implication of their choice of intervention procedures, the study uses the two main approaches of policy or program implementation-top-down and bottom-up to all governors, decision makers on possible ways to approach pandemic issues.

\section{ANALYTICAL APPROACHES TO IMPLEMENTATION THEORIES A CASE OF CORONAVIRUS (COVID-19)}

The Top-down approach put the policy as creators who in many cases are the governing body or president who focuses on the issue at hand and controlled it at the central level and more focus is placed on clear policies to 
address a situation (Matland, 1995). The decision makers who can be the president or the governing body are the ones responsible to give order on a how to address a situation faced in a state. Richard Matland (1995) also mentioned theories selected for implementation must be clear and consistent, must not have many people involved, a limit on the extent of change expected to see, due to implementation and also, an institution that would also be in support of the policy, be a focal point of information and share interest in the changes the new policy provides. While in the bottom-up approach, implementation is set on two parts according to Berman(1978) at the macro level of implementation, the governing body creates a policy program while at the micro level of implementation, the folks at the grassroots react to the plans created by the governing body, develop their own programs and implement them. When it comes to the method of approach to select when it comes to implementation, many would opt for a bottom-up approach because the workers and the implementation procedures can better judge the progress of the implementation procedures better than the policy makers because they get to witness the effects first hand. Palumbo, Maynard, \& Wright (1984) mentioned that if the policy enforcers are not awarded the liberty to access the progress of a program implementation and adapt to local conditions then the policy is doomed to fail.

Asides from the hierarchical level of the passage of orders, another major difference between the top-bottom and bottom-up approach is who gets involved in the implementation decision making; the top-down approach has a very low number of involved actors, it is more of a decision being made by the head and others are out to enforce. While the bottom-up has many actors involved to adjust the policy as it affects the target people involved in the policy to be implemented. The question then arises, if there is a one size fits all for the theory of program/policy implementation? The answer is No. This is because, the objective of the policy is a major factor to be considered and the actors who contribute to the policy implementation are factors to be considered when choosing an implementation approach or method. Given the underlying policy initiatives by the Chinese government, the implementation procedures by the Chinese was observed to be a top-down model or approach under an authoritarian type of government.

According to Meriam Webster this method is when all decisions are made, controlled or directed at the highest level. Basically, the residents of China were told what was going to happen, how it was going to happen and they had to comply. For example, according to the World Economic Forum, Speed and accuracy are the keys to identification and detection. Within a week of identification of the virus China successfully sequenced it and reported the genetic information to the World Health Organization (WHO). The identification is key to creating a vaccine for the virus. The next approach is the immediate measures, policies, and programs to fight pandemic across states.

The United States on the other hand, once it was impacted chose a bottom up model or approach. Merriam Webster argued that when the ideas and decisions are controlled or directed from the lower levels then such approach is bottom-up. Here, the President (or the executive branch) has elected to allow the Governors of each state to determine the course of action for their citizenry in the process of eradicating the pandemic. Only time will tell if this model is best as the country has recently began the plight.

\section{Summary of Effective Policy Strategies Adopted by Countries}

\begin{tabular}{|c|c|}
\hline Countries & Strategies \\
\hline $\begin{array}{l}\text { Hong Kong, } \\
\{454 \text { confirmed cases, } 4 \\
\text { deaths }\} \\
\text { Singapore, } \\
\{631 \text { confirmed cases, } 2 \\
\text { deaths } \\
\text { Japan } \\
\{1,291 \text { confirmed cases, } 45 \\
\text { deaths }\}\end{array}$ & $\begin{array}{l}\text { A research on resilience of systems in Hong Kong, Singapore and Japan has shown that } \\
\text { containment strategies there seem so far to have prevented widespread community } \\
\text { transmission. In these three countries surveillance systems were readjusted to identify } \\
\text { potential cases and their contacts, diagnostic tests were developed early on, and laboratory } \\
\text { testing capacity was increased. Different strategies were used to selectively control } \\
\text { travelers entering these locations, from partial entry restrictions (Singapore, Japan) to } \\
\text { mandatory 14-day quarantine (Hong Kong) of non-local visitors. Intra-governmental } \\
\text { coordination was improved based on the previous experiences during SARS and H5N1 } \\
\text { outbreaks. In all locations, all direct costs for treating patients are covered by the } \\
\text { governments, appropriate training and adherence to infection prevention and control } \\
\text { measures are practiced in hospitals. }\end{array}$ \\
\hline
\end{tabular}




\begin{tabular}{|c|c|}
\hline Countries & Strategies \\
\hline $\begin{array}{l}\text { South Korea } \\
{[9,241 \text { confirmed cases, } 131} \\
\text { deaths }]\end{array}$ & $\begin{array}{l}\text { Here the strategy has relied on active, free and massive screening (including drive-through } \\
\text { tests) for symptomatic individuals, case contacts and travelers. Schools have been closed, } \\
\text { working remotely is recommended, and large gatherings are banned. Mask wearing, } \\
\text { sanitizer use and thermal screening in buildings are widespread. Notably, there have been } \\
\text { neither lockdowns nor restriction to movement. The UNDP Seoul Policy Centre has } \\
\text { reviewed some outbreak-related practices in South Korea. Among these are disclosure of } \\
\text { real-time information on COVID-19 by the government via dedicated websites, mass } \\
\text { media, phone messages and mobile apps. Also, as of } 19 \text { March there were approximately } \\
85 \text { drive-through testing stations, and nearly } 20,000 \text { people are tested every day - more } \\
\text { tests per head of population than anywhere else. } \\
\text { People under compulsory self-quarantine (those awaiting the test results) are monitored } \\
\text { through an app by government and police, and violators are punished. Only people with } \\
\text { severe symptoms are hospitalized, the rest being sent home. Private sector companies } \\
\text { actively participate in disseminating and collecting virus-related information, which } \\
\text { includes data on confirmed coronavirus patients, along with the patient's nationality, } \\
\text { gender, age, which places the patient has visited, and how close citizens are to these } \\
\text { patients. } \\
\text { Telecom companies are providing the government with mobile data to monitor the } \\
\text { movement of COVID-19 patients. All of the above allow for more accurate estimations } \\
\text { and efficient misinformation and panic management. This strategy also facilitates cluster } \\
\text { identification and rapid self-quarantine, notes ISGlobal in their analysis. }\end{array}$ \\
\hline $\begin{array}{l}\text { China } \\
\text { [81,961 confirmed cases, } 3,293 \\
\text { deaths }]\end{array}$ & $\begin{array}{l}\text { China's approach included early lockdown and strict quarantine; severe restrictions on } \\
\text { international and domestic travel; use of health QR codes for permissions to move around } \\
\text { a city; frequent building and street sterilisation; testing, admitting and treatment of all } \\
\text { patients; and isolating suspected cases. The advantages of these were cooperation (even } \\
\text { if enforced), unburdening and rapid increase in the capacity of the health system (eg with } \\
\text { 'panic building' of hospitals). These early and drastic measures helped to delay the spread } \\
\text { of the virus from Hubei to other provinces. This is confirmed, for example, in an analysis } \\
\text { by a global consortium of researchers, led by the University of Oxford and Northeastern } \\
\text { University, which showed that human mobility played its role in the COVID-19 spread } \\
\text { in China, especially at the early stage. The implementation of travel restrictions resulted } \\
\text { in the decrease in this correlation and a much flatter epidemiological curve in most } \\
\text { locations. At that point, the authors say, public health response to curtail local } \\
\text { transmission (through testing, tracing and isolation) was most effective. The study } \\
\text { emphasizes that social distancing works - if not immediately. }\end{array}$ \\
\hline $\begin{array}{l}\text { Taiwan } \\
\text { [252 confirmed cases, } 2 \text { deaths] }\end{array}$ & $\begin{array}{l}\text { Taiwan has been another example of an efficient coronavirus strategy. Home to nearly } 23 \\
\text { million people, it was expected to have the second highest number of COVID-19 cases } \\
\text { due to its proximity to and close ties with China. But it had learned from the SARS } \\
\text { outbreak, when the National Health Command Centre (NHCC) was created as part of a } \\
\text { disaster management centre. The Central Epidemic Command Centre (part of NHCC) } \\
\text { introduced a number of immediate measures. Taking for example, inspecting plane } \\
\text { passengers coming from Wuhan starting from } 31 \text { December (when pneumonia cases were } \\
\text { announced) and banning entry for Wuhan residents on } 23 \text { January (when the province was } \\
\text { locked out). Other measures included case identification (using new data and technology), } \\
\text { quarantine of suspicious cases, proactive case finding and resource allocation, among } \\
\text { others. Taiwan's government stopped exports of surgical face masks on } 24 \text { January and } \\
\text { took charge over pricing and distribution. Local companies were asked to step up } \\
\text { production. The government also claimed a stockpile of surgical and N95 masks (which } \\
\text { have been divided between the public, medical and industrial sectors) and 1,100 negative- } \\
\text { pressure } \\
\text { Patients with severe respiratory symptoms were proactively identified (based on } \\
\text { information from the National Health Insurance database), citizens were asked to report } \\
\text { suspicious symptoms or cases via a hotline number. The authorities track down infected } \\
\text { persons and map the cases while residents' 14-day travel history is integrated with their } \\
\text { health insurance card data. Educating the public about the coronavirus-associated risks } \\
\text { and precautions has also been instrumental. }\end{array}$ \\
\hline
\end{tabular}

Table 1: Summary of Effective Policy Strategies Adopted by Countries to Contained the Spread of COVID-19 Source: Author's Modification of HealthManagement.org Most Effective Anti-COVID-19 Strategies 


\section{IDENTIFYING THE BEST APPROACH FOR UNITED STATES OF AMERICA}

In fact, in adopting any of the anti-COVID 19 strategies for implementation involves collective efforts from both the federal and the state governments. By all measures and policies, the federal government of the United States has been unable to handle the spread of the COVID-19 coronavirus. After weeks of insisting that the U.S. government was successfully fighting the spread of the deadly respiratory disease, President Trump on March 16, 2020 finally admitted that the contagion is "not under control" both in the U.S. and abroad (Clamp, 2020; Council on Foreign Relations, 2020; Scipioni, 2020). The White House guidelines recommend that Americans practice social distancing by avoiding groups of more than 10 people; the Centers for Disease Control recommended that all gatherings of more than 50 people be cancelled for up to eight weeks as authorities work feverishly to halt the spread of the virus (World Health Organization, 2020; Centers for Disease Control and Prevention, 2020). Currently, there are more than 867,771 confirmed coronavirus cases, 48,900 deaths and 79,817 recovered across the country as at April 23, 2020, according to the New York Times tracker. Meanwhile, the federal authorities have predicted that the pandemic will last up to 18 months but cases are getting alarming across states. In fact the Coronavirus has been observed to ground American life to a halt. Meanwhile, the most horrible part of the coronavirus pandemic is not how much of a surprise it came to the majority of the Americans, but how absolutely unsurprising it was - and how ill-equipped the U.S. government was on everything from funding to supplies to tackling the coming COVID 19 crisis.

The most appropriate approach to the implementation of the WHO protocols to aid in the flattening of the curve in the United States of America - is the synthesis of both the Top-down and Bottom-up approaches. The applications of the two approaches are expected to aid in the successful policy implementation in the present of Covid-19 pandemic. According to OECD (2013), synthesizing the two approaches would draw on the strengths of both the top-down and bottom-up thereby minimizing the weaknesses. The success of this approach is drawn from the assumption that stakeholder interacts at different levels-this is the policy makers and the local actors on ground for implementation. Suggett (2011) in his article titled, "the Implementation challenge: strategy is only as good as its execution" argued that synthesizing both approaches are the best methods to tackle issues in healthcare, taxation, education and pandemic related issues. During this particular period of this COVID 19 outbreak, the federal government is expected to be working closely and hand-in-hand with the "state, local, tribal and territorial partners" as top-down approach of policy implementation to combat this current plague. With respect to the top-down approach, the federal government is expected to initiate all the policies and programs intervention that needs to be trickle-down to the various states for implementation. Some of the federal level policies may include initiating nation-wide lockdown, nation-wide wearing of masks, policies on testing, social distancing, curfews, event postponement and cancellation, releasing funds to purchase health equipment such ventilators, nose masks, and many others.

From the stakeholders mentioned it is clear that the approach involves/includes the bottom-up approach to monitor, enforce and revert back to the federal government. Also, the Federal government and President of the United States of America extended a "lockdown" for the nation to practice social distancing (CNN, 2020). This has been enforced in the many states in the country to tackle the spread of the virus while a vaccine and cure is being worked on. The order given from the president and enforced by mayors and state governors falls under the alley of Top-Bottom approach of program implementation.

The synthesis of both approaches is the best way to tackle the virus because this virus is unlike other viruses or illness that has been experienced before. With each passing day, new discoveries are observed, and testing is still ongoing. In order to slow the spread because the nation does not also have enough ventilators to cater for those currently infected and in need (New York Times, 2020). The best approach right now is to curtail the spread and that is where all parties from the head of the country to the state and grass-root has to be on the same page asides from give orders from the top but also, receive information and feedback on the current situation and report on what is going on at the grass root and if there is a need to adjust or fine-tune an order. This employs the expertise of both the "Top-down" and "Bottom-up" approach. In the face of the bottom-up approach the states governors and mayors are also expected to work hand-in-hand at the state and the local level to implement the federal policies with the enforcement and directives all coming from the federal government. Here, mayors are expected to interact and enforces the policies at the parish levels with the help of the state governors. The report generated from the enforcement and the implementation of the policies (or the WHO protocols) initiated by the federal government at the local and state levels By so doing the utilization of the two implementation approaches are expected to flatten curve of the spread of the COVID 19 pandemic. Above all, what is not talked about and is extremely important with the deadly COVID 19 pandemic is the building of the citizen's immunity. I observed in the medical literature that the human body is able to fight all kinds of diseases whenever it builds high immunity. That is why people with underlying medical issues like hypertension, diabetes, cancer and other chronic diseases are more susceptible to the COVID 19 virus. Such individuals have low immunity. Therefore, in order to build immunity, Vitamin C and zinc consumptions are the natural ways to build high immunity. Naturally, Vitamin $\mathrm{C}$ can be obtained from the consumption of fruits like lemon, oranges, pineapples and zinc can also be obtained from watermelon seeds. 


\section{REFERENCES}

Centers of Disease Control and Prevention.(2020). "Symptoms of Novel Coronavirus (2019-nCoV)". US Centers for Disease Control and Prevention. 10 February 2020. Retrieved 11 February 2020.Centers of Disease Control and Prevention. (2020). "Coronavirus Disease 2019

Information for Travel". US Centers for Disease Control and Prevention (CDC). 3 February 2020. Archived from the original on 30 January 2020. Retrieved 6 February 2020.

Clamp, R. (2020). "Coronavirus and the Black Death: spread of misinformation and xenophobia shows we haven't learned from our past". The Conversation. Retrieved 14 March 2020.

Council on Foreign Relations. (2020). "The Coronavirus Outbreak Could Disrupt the U.S. Drug Supply". Council on Foreign Relations. Retrieved 19 March 2020.

Deerwester, J.; Gilbertson, D. (2020). "Coronavirus: US says 'do not travel' to Wuhan, China, as airlines issue waivers, add safeguards". USA Today. Archived from the original on 27 January 2020. Retrieved 26 January 2020.

Durlak, J. A. (2011). The Importance of implementation for research, practice, and policy. Child Trends research brief. Washington, DC: Child Trends. Retrieved from http://www.childtrends.org/wpcontent/uploads/2013/05/2011-34DurlakImportanceofImplementation.pdf.

Folland, S. Goodman, A. C \& Stano, M., (2004)."The Economics of Health and Healthcare, $4^{\text {th }}$ Edition" Upper Saddle River: Pearson Prentice Hall.

Hjelmgaard, K., Lyman, E., and Shesgreen, D. (2020, April 1). This is what China did to beat coronavirus. Experts say America couldn't handle it. Retrieved https://www.usatoday.com/story/news/world/2020/04/01/coronavirus-covid-19-china-radical-measureslockdowns-mass-quarantines/2938374001/

Ignatius, D. (2020, April 2). Opinion | How did covid-19 begin? Its initial origin story is shaky. Retrieved from https://www.washingtonpost.com/opinions/global-opinions/how-did-covid-19-begin-its-initial-origin-storyis-shaky/2020/04/02/1475d488-7521-11ea-87da-77a8136cla6d story.html

Oseni, A. A. and Akinsanmi, T. (2020). A Review of the Children's Health Insurance

Program Reauthorization Act (Chipra) and its implementation in Louisiana, USA. Journal of Public Policy and Administration Research, Vol.10, No. 2 (2020)

Wang, X., Wu, X. and Xu, X. (2020, March 12). 6 lessons from China's Zhejiang Province and Hangzhou on how countries can prevent and rebound from an epidemic like COVID-19. Retrieved from https://www.weforum.org/agenda/2020/03/coronavirus-covid-19-hangzhou-zhejiang-government-response/ 